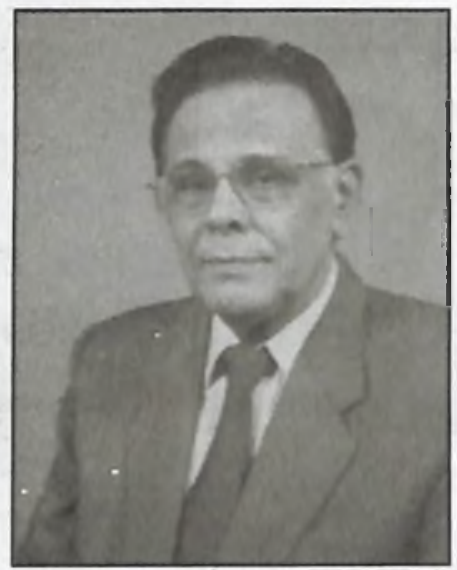

\title{
Message from the President
}

Dear friends,

You may be aware that following the successful organization of the International Welding Congress, IIW-IC-2008 recently held in Chennai in January 2008, the International Institute of Welding has further awarded us to conduct the most prestigious event, the Annual Assembly in India in 2011. The National council of our Institute at their 261st Meeting held in Mumbai on 12th April 2008 has unanimously decided that the total event will be organized in Chennai. Although a national organizing committee would be constituted in due course, for efficient organization of this prestigious mega event, the primary responsibilities have been divided among 3-Branches viz. Kolkata, Chennai and Mumbai. Kolkata Branch will be responsible for the international assembly, while management of the international congress and the exhibition (which will be concurrently held) would be the task of Mumbai Branch and Chennai Branch respectively. I request wholehearted support from all of you in advance to make this event a grand success.

The National Welding Meet (NWM'08) of this year will be held on Saturday, the 23rd August 2008 at the Training \& Development Centre, Visakhapatnam Steel Plant, Visakhapatnam, to be organised by the Vizang Branch on the theme "Current Trends in Joining Emerging Materials in Process Industry". Please participate in this event.

The National Welding Seminar 2008, the prime national event of the Institute, will be held on 4th-7th February 2009 in Mumbai to be organized by the Mumbai Branch. During this event, an Exhibition will also be held. Mumbai Branch is about to release their first information and call for papers.

With all my best wishes.

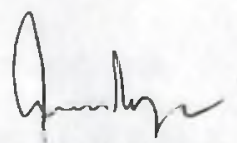
A. K. Mukherjee

President 